\title{
An Experience with Neonatal Ventilation in Eastern U.P.
}

Sir,

Neonatology has really picked up as a superspeciality with most of the big hospitals and medical colleges coming up with a separate intensive care unit for the neonates. But still a lot is desirable in terms of availability of good quality equipment and trained medical and paramedical personnel. We did a retrospective observational study in the NICU of our medical college in eastern U.P. in which we collected data regarding all the babies weighing $>1 \mathrm{~kg}$ who received assisted ventilation over a period of $18 \mathrm{mo}$ from October 2006 to March 2008. All the babies were ventilated with Inspirator (Erkadi Ltd) and put on synchronized pressure controlled intermittent ventilation (P-SIMV) which was time cycled, pressure limited with continuous flow or continuous positive airway pressure (CPAP). Data of 68 babies with a birth weight $>1 \mathrm{~kg}$ who were given assisted ventilation was analysed. Only 10 babies received CPAP alone. Overall survival amongst these ventilated neonates was $48.5 \%(33 / 68)$. Sepsis was the most common indication for giving mechanical ventilation(41\%) followed by meconium aspiration syndrome(21\%). Surprisingly RDS was responsible for ventilation in only $6(9 \%)$ neonates. We were not able to give surfactant in any of these babies because of financial constraints. Survival was worst in babies weighing $<1.5 \mathrm{~kg}(40 \%)$ and those $<32 \mathrm{wk}$ of gestation(36\%). The survival was comparable in babies $32-36 \mathrm{wk}$ and those $>36 \mathrm{wk}(52 \%)$. The survival of babies with birth weight $>1.5 \mathrm{~kg}$ and $<2.5 \mathrm{~kg}(55 \%)$ was better than those weighing $>2.5 \mathrm{~kg}(47 \%)$.

Although the western countries report a very high survival rate among the ventilated newborns, the Indian studies have reported a survival rate varying from $46.5 \%$ to $55.8 \% .^{1,2,3}$ These studies are usually from apex institutes where infrastructure is much better as compared to ours. An NICU catering to the very poor and backward area where newborns are referred late and reach late is bound to have a low survival rate even after the best care. We are situated in eastern Uttar Pradesh which is among the more backward areas of our country. We cater to an area that is mainly rural and backward and female literacy is abysmally low and neonatal and infant mortality is very high compared to the national figures.

Most of the earlier studies have reported RDS as the commonest indication. ${ }^{1,3}$ But septicemia was the commonest indication in a study by Krishnan et $a l^{5}$ Although majority of those ventilated were preterms 41/
$68(60 \%)$ but most of them presented to us with septicemia and not RDS. A reason for this could be that we received most the babies late by which time those with moderate to severe RDS expired and did not reach us and those with mild RDS survived at the peripheral center and later on when they deteriorated due to sepsis were referred to us. As majority of our ventilated babies were outborns $(88 \%)$, so the incidence of sepsis was higher. Meconium aspiration syndrome was the next most common indication. This is again explainable by the fact that we cater to mostly rural and poor population where home deliveries are quiet common and even those delivering in the hospitals hardly receive optimum care during labour and delivery increasing the number of cases of fetal distress and obstructed labour.

There are a lot of limitations and shortcomings of the health infrastructure in eastern UP leading to a very high NMR. Majority of our admissions were outborns who hardly received any optimum medical treatment before referral and during transport. Inspite of all these factors we were able to achieve a survival rate among ventilated neonates which is comparable to other studies conducted in the past from other states with much better health infrastructure.

\author{
Ruchi Rai and D.K. Singh \\ Department of Pediatrics, M.L.N. Medical College, \\ Allahabad, U.P, India \\ E-mail:drruchi.rai@indiatimes.com
}

\section{REFERENCES}

1. Nangia S, Arwind S, Datta AK, Vani G, Meeta S, Anju S et al. Neonatal mechanical ventilation-experience at a level II care center. Indian J Pediatr 1998; 65: 291-296.

2. Riyas PK, Vijayakumar KM, Kulkarni ML. Neonatal mechanical ventilation. Indian J Pediatr 2003; 70 : 537-540.

3. Mathur NC, Sailesh K, Prasanna AL, Sahu UK, Kapoor R, Roy $\mathrm{S}$ et al. Intermittent positive pressure ventilation in a neonatal intensive care unit: Hyderabad experience. Indian Pediatr 1998; 35: 349-352.

4. Maiyya PP, Vishwanath D, Hegde S, Srinivas TP, Prasad S, Shantala $C$ et al. Mechanical ventilation in newborns: Experience from a level II NICU. Indian Pedaitr 1995; 32: 12671274.

5. Krishnan L, Paul PF, Nirupa AD, Nalini B. Assisted ventilation in neonates-A Manipal experience. Indian J Pediatr 1994; 61: 379-386. 